Journal of Marketing Research

Article Postprint

Volume XLV

(9) 2008, American Marketing Association

Cannot be reprinted without the express

permission of the American Marketing Association.

Me, Myself, and My Choices:

The Influence of Private Self-Awareness on Choice

\title{
CAROLINE GOUKENS
}

\section{SIEGFRIED DEWITTE}

LUK WARLOP* 
*Caroline Goukens is Assistant Professor of Marketing at Maastricht University, Dept of Marketing, P.O. Box 616, 6200 MD Maastricht, The Netherlands (Tel: +31 (0) 433884825 - Fax: +31 (0) 43884918) (c.goukens@mw.unimaas.nl). Siegfried Dewitte is Associate Professor of Marketing at K.U.Leuven, Dept of Marketing and Organization, Naamsestraat 69, 3000 Leuven, Belgium (Tel: +32 (0) 16326949 - Fax: +32 (0) 16326732) (siegfried.dewitte@econ.kuleuven.be). Luk Warlop is Professor of Marketing at K.U.Leuven, Dept of Marketing and Organization, Naamsestraat 69, 3000 Leuven, Belgium (Tel: +32 (0) 16326941 - Fax: +32 (0) 16326732) (luk.warlop@econ.kuleuven.be). The authors thank Katholieke Hogeschool Kempen for their generous cooperation with the data collection for Study 2. They also thank all members of the consumer behavior group at K.U.Leuven for helpful comments on a previous version of this manuscript. They gratefully acknowledge financial support from the Fund for Scientific Research-Flanders, Belgium (grant 3H.03.0304 and 03.0391), Katholieke Universiteit Leuven (OT/03/07), and Censydiam-Synovate. 


\begin{abstract}
This article examines the impact of private self-awareness on consumer decision making. In four studies, the authors show that the ease of preference formation accompanying private self-awareness makes people more willing and able to rely on their personal preference weights. As the authors predict, privately self-aware consumers are less inclined to opt for a varied choice set (Study 1) and less likely to select compromise options (Studies 2 and 3), unless it is too difficult for them to construct their personal preferences (Study 4).
\end{abstract}

Keywords: self-awareness, variety-seeking, compromise effect, preference formation, consumer choice 
Self-awareness rests at the core of a person's sense of self; thus, the human capacity to direct attention toward the self has fundamental personal, social, and cultural consequences (May 1967). According to original self-awareness theory (Duval and Wicklund 1972), self-focused attention makes people more conscious of their attitudes and beliefs (Gibbons 1990). Moreover, cognitive dissonances and inconsistencies become much more aversive when people direct their attention to the self. Spurred by this finding, social psychologists have investigated the implications of self-awareness for a variety of basic social and cognitive processes (e.g., emotions, prosocial behavior, group dynamics; for a review, see Gibbons 1990).

We focus on the influence of private self-awareness in the choice-making process and examine how this internal state affects two well-known choice phenomena: varietyseeking and the selection of a compromise option. Previous research demonstrates that both variety-seeking and compromise options reflect the difficulty associated with trading off among specific aspects of provided options (Simonson 1989, 1990). By manipulating self-awareness, we reveal that increased preference fluency (defined by Novemsky et al. (2007) as 'the consumers' subjective feeling about the ease or difficulty of forming a preference for a specific option.”), accompanying private selfawareness, makes people more willing and able to rely on their personal preference weights. More specifically, privately self-aware consumers are less inclined to opt for a varied choice set and less likely to select compromise options.

We start with a brief review of self-awareness theory, then introduce the concept of private self-awareness in choice processes and report on four experiments in which we examine the influence of self-awareness on the selection of compromise options or varied choice sets. We also take a closer look at the processes that underlie the reported 
effects and potential boundary conditions. Finally, we discuss the implications of these findings with regard to the role of private self-awareness in consumer decision making and for managerial tactics that might promote self-awareness and thus influence purchase decisions.

\section{SELF-AWARENESS THEORY}

Original self-awareness theory (Duval and Wicklund 1972) starts from the assumption that at any given time, people's attention may be focused on themselves or the environment but not both. People usually are not self-focused, but certain situations can cause them to focus their attention inward, such as gazing into a mirror, standing in front of an audience, or seeing themselves in a photograph or videotape. When their attention gets directed to the self, people reside in a state of objective self-awareness.

Further developments of self-awareness theory (e.g., Buss 1980; Carver and Scheier 1981; Froming, Walker, and Lopyan 1982) distinguish between public and private selfawareness. Public self-awareness involves the awareness of oneself from the imagined perspective of others (e.g., standing in front of an audience), whereas private selfawareness refers to awareness of oneself from a personal perspective (e.g., gazing into a mirror) (Fejfar and Hoyle 2000). Attention to the private self results in behavior that reflects personal attitudes, whereas attention to the public self tends to cause behavior to become more consistent with societal expectations (Froming, Walker, and Kopyan 1982). The effects of public self-awareness, often induced by the presence of an audience or video camera, on preference-behavior consistency also appear in consumer behavior research, most notably that by Ariely and Levav (2000) and Ratner and Kahn (2002), which reveals that the presence of an audience during a choice induces people to switch away from their preferred items. 
The concept of private self-awareness, in contrast, has received little attention in marketing literature. We consider the extent to which private self-awareness might play a role in consumer decision making: A self-focused person is more concerned with which type of action is most appropriate. If a person perceives a discrepancy between a standard and current behavior, his or her self-focus should enhance the motivation to reduce that discrepancy (Gibbons 1990). Thus, when possible, a self-aware person conforms to internalized standards of correct behavior, which may or may not coincide with the common social standard of conduct. For example, self-focused attention decreases cheating (Vallacher and Solodky 1979) and increases willingness to help (Berkowitz 1987). Sometimes though, no behavioral standard may be accessible. Experimental research (e.g., Hormuth 1982) suggests that in this case, privately selfaware persons behave in a manner congruent with their own personal standards or ideas (Gibbons 1990). That is, previous research demonstrates that self-focused persons become more conscious of their personal attitudes and beliefs (Gibbons 1990), which should make it easier for them to construct product preferences. Consistent with the account provided by Dijksterhuis and Knippenberg (2000), heightened private selfawareness can make people more willing and able to use their personal characteristics as guides for their behavior. Therefore, we expect self-aware consumers to rely more on their personal, idiosyncratic preference weights and to be less inclined to select compromise options or varied choice sets.

\section{HYPOTHESES DEVELOPMENT}

We focus on the role of private self-awareness in the choice-making process of consumers and examine how this internal state may affect two well-known choice phenomena: variety-seeking (Study 1) and the selection of a compromise option 
(Studies 2 and 3). We also consider the underlying decision processes and possible boundary conditions (Study 4).

Variety-Seeking

When consumers make multiple purchases for several consumption occasions, they tend to select a greater variety of items than they would if they were making purchases sequentially. Variety-seeking in this case appears to be due to uncertainty about future preferences at the time of consumption, particularly because of unknown changes in states of mind and tastes (Simonson 1990). Kahneman and Snell (1992) present empirical evidence that people's ability to estimate future preference volatility is rather poor, as is their ability to predict future preferences. Therefore, purchasing the same item for all periods creates a risk of cumulative disappointment should the consumers' preference for that item decrease in the near future, perhaps due to satiation. In contrast, selecting a variety of acceptable items is less risky, because it seems unlikely that the person's preferences for all selected items will decrease. A person who consumes a can of soup each week and buys a month's supply of soups may be reluctant to purchase only chicken noodle, because his or her liking for that soup might decrease at some point (Simonson 1990). Moreover, determining which of the considered options actually is the most preferred might require time and cognitive effort (Payne, Bettman, and Johnson 1988). Therefore, to simplify the task, the consumer selects a set of attractive candidates, which eliminates the need to determine which is the most preferred (Simonson 1990). Because private self-awareness should enhance preference fluency, we also expect it to decrease the tendency to seek variety. 
$\mathrm{H}_{1}$ : $\quad$ Privately self-aware consumers who simultaneously choose multiple items are less likely to diversify their choice set than are non-privately self-aware consumers.

\section{Compromise Effect}

The compromise effect offers a second suitable research hypothesis regarding the moderating effects of private self-awareness on people's ability to rely on their own personal preference weights. The compromise effect refers to the phenomenon by which options with extreme values on some key attribute dimensions appear less attractive in the presence of options with "safe" intermediate values than they would in the absence of those compromise options. This effect implies that an alternative tends to gain market share when it represents the compromise option in the set (Simonson 1989). For example, the attractiveness of a medium-quality/medium-price alternative increases in comparison with that of a lower-quality/low-price alternative when a high-quality/highprice product also appears in the consideration set, because it becomes the "ideal" compromise of quality and price.

Simonson (1989), using think-aloud protocols, finds that people who experience greater decision conflict are more susceptible to the compromise effect. Consistently, when people select compromise alternatives, their decision protocols are longer (Dhar, Nowlis, and Sherman 2000), they tend to consider the relative advantages and disadvantages of all options (Simonson 1989), and they are more likely to attempt compensatory trade-off comparisons (Dhar 1996). In contrast, consumers with more articulated preferences (i.e., preference fluency) are more selective in processing the available information and less likely to rely on compensatory processing (Chernev 
2003). Combining both insights, we suggest that private self-awareness may suppress the tendency to select compromise options, such that

$\mathrm{H}_{2}$ : Because private self awareness enhances preference fluency, self-aware consumers are less likely to choose a compromise option than are nonself-aware consumers.

In an effort to test these hypotheses, we conduct four experiments in which we manipulate private self-awareness. In Study 1, we show that private self-awareness reduces consumers' natural tendency to switch away from their favorite choice options: More self-aware participants opt for a varied choice set less often than do non-selfaware participants. In Study 2, we demonstrate that self-aware participants are less likely to choose a compromise option than are non-self-aware participants. In Study 3, we replicate these findings and further show that these effects result from increased preference fluency.

Finally, in Study 4, we provide further evidence that reveals self-aware consumers are not only more selective in their information acquisition but also more likely to search by alternative, a characteristic of clear personal preferences. We also demonstrate that hindering preference construction mitigates the effect of private selfawareness on preference-behavior consistency.

\section{STUDY 1}

The primary objective of our first study is to examine the effect of private selfawareness on variety-seeking behavior. To that end, we induce self-aware versus nonself-aware participants to make selections from a choice set of different juices. These choices are consequential; every participant is entered in a lottery that might award them their choice. To measure variety-seeking, we consider the number of different 
juices participants order. The measurement of overall preferences for the different alternatives also enables us to test whether participants' state of private self-awareness influences the consistency between their preferences and their actual choices.

In addition, we hope to illustrate that public and private self-awareness have different effects on choice. That is, though both may increase consumers' attempts to match a standard, attention to the private self should result in behavior that reflects personal attitudes, whereas attention to the public self causes behavior that appears more consistent with societal expectations (Froming, Walker, and Lopyan 1982). Previous consumer behavior research (Argo, Dahl, and Manchada 2005; Ariely and Levav 2000; Ratner and Kahn 2002) finds that when decisions are subject to public scrutiny, people often switch away from their preferred items, because they expect the choice to be evaluated as more socially rewarding than their preferred option. In contrast, we expect to find the opposite effect for private self-awareness: As private self-awareness increases participants' consciousness of their personal attitudes, it also should increase the ease of constructing a personal preference for each choice option. Therefore, private self-awareness should increase preference-behavior consistency. At least at a theoretical level, there are several good reasons to expect differential effects of public and private attention on choice; we contrast these two types of self-awareness to test this theory. Thus, we assign participants randomly to one of three conditions (control, private self-awareness, or public self-awareness).

\section{Method}

Participants include 116 undergraduate students (45 men, 71 women) at a large university, who receive $€ 6$ for participating in this and other unrelated studies. Two participants for whom we lack complete data are excluded from the analyses. In the 
beginning of the experimental session (preference phase), we asked all participants to complete a questionnaire, which they were led to believe had been distributed by a beverage retailer. This questionnaire measured personal liking for various drinks (including fruit juices) on a five-point scale $(1=$ don't like it at all; $5=$ like it very much). We opted for this product category because it is relevant to students and consumers often make multiple purchases in this category within a short period of time. In addition, this product typically is consumed completely during one consumption occasion.

Next, we asked participants to complete a survey containing an arousal-seeking tendency scale (AST), private and public self-consciousness (SC) scales, and some demographic questions. The first scale (Mehrabian and Russell 1974) consists of 32 items $(\alpha=.89)$ measured on a nine-point scale. The private SC scale consists of 10 items $(\alpha=.74)$ (see Appendix A), whereas the public version consists of seven $(\alpha=$ .76). Both SC measures use six-point Likert-type scales (Fenigstein, Scheier, and Buss 1975). Participants' AST and private and public SC scores served as control variables in all analyses.

Finally, at the end of the experimental session (choice phase), we introduced an additional reward for participating, telling participants that the soft drink service that organized the inquiry agreed to award a gift basket filled with exotic fruit and six bottles of fruit juice to winning participants. To participate in the lottery, the participants had to indicate on a contest form which types of juice they would like, choosing six out of eight flavors (apple, orange, apple-cherry, lemon, passion fruit, mango, peach, and strawberry). In all conditions, participants completed this choice task just before leaving the lab. In the private SC condition, we manipulated self-awareness by placing a mirror 
in front of the table on which they completed the final choice task. In line with Carver and Scheier (1978), the mirror $(40 \mathrm{~cm} \times 120 \mathrm{~cm})$ was affixed to the wall behind the table, approximately $1 \mathrm{~m}$ in front of the participants and at their eye level. In the public SC condition, a colleague sat at the table less than 2 feet from where the participants completed the final task. This person observed the choices made, under the guise of an administrative check, and avoided interacting with the participants (Argo, Dahl, and Manchada 2005). This manipulation of public self-awareness (Buss 1980) effectively focuses participants' attention on the self from an external perspective (i.e., "What is that person expecting me to do?" or "What does he or she think of my behavior?").

Finally, participants dropped their form in a box before leaving the lab. Later, we drew eight forms from this box and notified the winners.

\section{Results and Discussion}

Choice results. We measure variety according to the number of different fruit juices participants ordered on the contest form. An ANOVA reveals a significant effect of private self-awareness on variety-seeking behavior $(\mathrm{F}(2,108)=7.73, p<.001)$, such that participants in the private self-awareness condition select significantly fewer juices than participants in the control condition $\left(\mathrm{M}_{\text {private }}=3.19, \mathrm{SD}_{\text {private }}=.20 ; \mathrm{M}_{\text {control }}=3.74\right.$, $\left.\mathrm{SD}_{\text {control }}=.21 ; \mathrm{F}(1,69)=4.45, p<.05\right)$ or participants in the public self-awareness condition $\left(\mathrm{M}_{\text {public }}=4.28, \mathrm{SD}_{\text {public }}=.20 ; \mathrm{F}(1,75)=13.24, p<.001\right)$. These results support our hypothesis that private self-awareness decreases the tendency to seek variety and thereby provide initial evidence that self-aware consumers experience less difficulty in constructing their personal preferences and therefore are less inclined to select a varied choice set. 
Consistent with previous research (Ariely and Levav 2000; Ratner and Kahn 2002), participants in the public self-awareness condition include more variety in their choices than those in the control condition $(\mathrm{F}(1,69)=4.39 ; p<.05)$. Thus, public selfawareness appears to trigger the desire to be evaluated positively as an interesting person.

\section{Effect of self-awareness on preference-behavior consistency. Using participants'} personal liking ratings of each fruit, we compute the consistency between these ratings and their choices on the contest form (see Appendix B). This consistency score equals 1 if the person chooses only his or her favorite options and 0 if he or she chooses only juices with the lowest scores in the preference phase. Consistent with the notion that private self-awareness should increase participants' consciousness of personal attitudes, we find that participants in the private self-awareness condition stick with their favorite drinks, more so than participants in either the control condition $\left(\mathrm{M}_{\text {private }}=.88, \mathrm{SD}_{\text {private }}=\right.$ $\left..02 ; \mathrm{M}_{\text {control }}=.82, \mathrm{SD}_{\text {control }}=.03 ; \mathrm{F}(1,69)=4.15, p<.05\right)$ or the public self-awareness condition $\left(\mathrm{M}_{\text {public }}=.75, \mathrm{SD}_{\text {public }}=.02 ; \mathrm{F}(1,75)=12.65, p<.001\right)$. Thus, in the private self-aware condition, personal preferences provide a much stronger predictor of choice than they do in the control or the public self-awareness condition.

We also replicate Ratner and Kahn's (2002) finding that the desire to be evaluated favorably by others can lead consumers to switch away from their favorite item(s). Participants in the public self-awareness condition opt for their favorite drinks less than do participants in the control condition $(\mathrm{F}(1,69)=3.90 ; p=.05)$. Thus, though both private and public self-awareness increase consumers' efforts to match a standard, attention to the public self causes their behavior to become less consistent with their personal attitudes, whereas attention to the private self results in behavior that reflects 
those personal attitudes. We attribute the latter result to the greater ease of constructing a personal preference for each choice option in a state of private self-awareness.

\section{STUDY 2}

With Study 1, we confirm that increased preference fluency because of private selfawareness reduces variety-seeking. However, preference fluency also may influence the option chosen within a choice set, perhaps even decreasing the attractiveness of a compromise option (Novemsky et al. 2007). Many consumers who select the compromise option find the entire decision difficult and view the middle option as a way to resolve this difficulty. In the same way as private self-awareness produces effects on variety-seeking, we propose that private self-awareness, by facilitating the formation of personal preferences, attenuates the tendency to select compromise options.

\section{Method}

Participants are 82 college students ( 44 men, 38 women) fulfilling a course requirement. One participant for whom we lack complete data is excluded from analyses. We informed participants that the experiment pertains to the relationship between writing styles and choice behavior. Thus, we manipulated three factors in a $2 \times$ $2 \times 2$ (i.e., self-awareness $\times$ choice set size $\times$ product category) between-subjects design.

Participants first constructed a story from a given set of words (story writing task) as a measure of their "writing style." Participants in the high self-awareness condition wrote a story about themselves, whereas those in the low self-awareness condition wrote a story about the king of Belgium. In line with Fenigstein and Levine (1982), we gave all participants a list of 20 words that they must use in their stories. Whereas 15 
words remained the same across both conditions, we varied 5 words to manipulate selfawareness. In the high self-awareness condition, the list included I, me, myself, alone, and mirror; in the low self-awareness condition, the list featured he, himself, him, together, and picture. Writing stories using self-relevant or other-relevant words should help force participants to direct their attention either toward or away from themselves. They had 10 minutes to create and write their stories.

Upon completion of this first task, participants were asked to make a product choice. Half the participants chose from a two-option choice set, and the other half considered a three-option choice set. The three-option set contained both product options from the two-option set with another, more extreme option, which turned one of the two existing options into a compromise options. We also used two product categories as an initial attempt to generalize across situations. We present the choice sets in Appendix B.

In addition to their size, the sets varied with respect to the product category they represented (apartments or mobile phones). The description of each alternative included two attributes, and the study design indicated the alternatives are similar in all other attributes. We attempted to include only product categories relevant to college student participants. Finally, we included apartment renting status and mobile phone ownership as control variables in all analyses.

\section{Results and Discussion}

Choice results. As we show in Appendix C, option B appears in both the two- and the three-option set, in which it represents the compromise option. Binary logistic regression reveals that the impact of the set size on the choice of option B is moderated by self-awareness (Wald $\chi^{2}(1)=4.68, p<.05$ ), and the effect does not differ between 
product classes (apartment versus mobile phone), according to a three-way interaction: Wald $\chi^{2}(1)=.93$, NS.

To gain better insight into this interaction, we address the effect of set size in the private self-awareness and control conditions separately by comparing the share of option B in the two-option set with its share in the three-option set. That is, across the two self-awareness conditions, we test the share of option B in the two-option set against its share in the three-option set relative to the other option available in the twooption set.

Consistent with previous studies, in the low self-awareness condition $(n=39)$, the

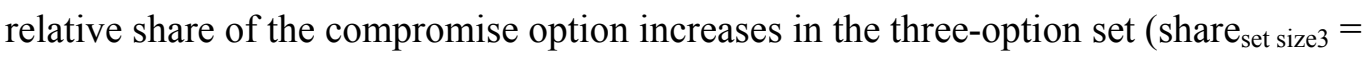
$82.3 \%$ ) compared with the two-option set $\left(\right.$ share $_{\text {set size } 2}=36.3 \%$; Wald $\chi^{2}(1)=7.62, p<$ .01 ). We find this increase for both the apartment category $\left(\right.$ share $_{\text {set size } 2}=25 \%$, share set size $3=80 \%$, Wald $\left.\chi^{2}(1)=5.77, p<.02\right)$ and the mobile phone category $\left(\right.$ share $_{\text {set size } 2}=$ $50 \%$, share set size $3=86 \%$, Wald $\left.\chi^{2}(1)=3.12, p<.08\right)$. Thus, the probability of choosing an alternative increases when it becomes the compromise choice.

In contrast, in the high self-awareness condition $(n=42)$, the context effect declines, such that the relative share of option B is not significantly different in the binary $\left(\right.$ share $\left._{\text {set size } 2}=31.6 \%\right)$ and tri-choice $\left(\right.$ share $_{\text {set size } 3}=38.9 \%$; Wald $\chi^{2}(1)=.27$, NS $)$ sets, whether we consider participants who choose among apartments $\left(\right.$ share $_{\text {set size } 2}=22 \%$, share $_{\text {set size } 3}=30 \%$, Wald $\left.\chi^{2}(1)=.74, \mathrm{NS}\right)$ or mobile phones $\left(\right.$ share $_{\text {set size } 2}=40 \%$, share set size3 $=50 \%$, Wald $\left.\chi^{2}(1)=.05, \mathrm{NS}\right)$. We summarize these data in Table 1.

\section{$\underline{\text { Insert Table } 1 \text { about here }}$}

Study 2 thus provides initial evidence that private self-awareness reduces the tendency to opt for the compromise option. We find an almost complete suppression of 
the otherwise robust tendency to opt for compromise options. The observed results further suggest that people who are self-aware experience higher preference fluency. To test this conjecture, we conduct Study 3.

\section{STUDY 3}

With Study 3, we attempt to improve confidence in the mechanism underlying the effects we describe previously. That is, we argue that the effect of private selfawareness on choice may be explained by increased preference fluency. We explicitly test the assumption that self-aware consumers can form preferences more easily by (1) measuring preference fluency and then (2) manipulating preference fluency.

As a measure of preference fluency in a certain product category, we register the time participants need to identify the three most important option attributes during a choice. Thus, we assign them randomly to one of three conditions (control, selfawareness, or preference awareness) and manipulate private self-awareness in the same way as in the first experiment, namely, affixing a mirror $(40 \mathrm{~cm} \times 120 \mathrm{~cm})$ to a wall behind a table during the experiment. To enhance preference fluency, we increase participants' access to their personal preferences. Specifically, in line with Chernev (2003), participants in the preference awareness condition engage in a preference articulation task that asks them to describe their ideal choice from among the given product categories prior to each choice task. This manipulation increases preference fluency during a choice task (Chernev 2003), as we outline in more detail next.

\section{Method}

A total of 109 undergraduate students (53 men, 56 women) participated in this experiment, though 4 participants suspicious about the presence of the mirror were deleted from the analysis. Furthermore, we omitted 2 outliers $(1.9 \%)^{1}$ from the analyses. 
All participants made choices in two product categories: apartments and mobile phones, in randomly determined order. All decisions involved three alternatives, with each alternative defined on two attributes. The choice sets were similar to the tri-option choice sets in Study 2 and included a compromise option (see Appendix C).

Before making these choice decisions, participants in the preference awareness condition described their ideal choice (Chernev 2003), such as, "My ideal apartment is big, clean and bright. I would also like a small garden.” Thus, all participants made a choice in each product category, but only those in the preference awareness condition stated their preferences by identifying their ideal choice first. A pretest with the same conditions $(n=100)$ indicated that private self-awareness was comparable in the preference awareness and control conditions and lower than in the private selfawareness condition. In the self-awareness condition $(M=5.47)$, using a seven-point scale, participants reported thinking more about themselves when completing the task than participants in the control condition $(\mathrm{M}=4.43 ; \mathrm{F}(1.65)=7.06, p=.01)$ or the preference awareness condition $(\mathrm{M}=4.58 ; \mathrm{F}(1,63)=6.58, p=.01)$.

Next, we asked all participants which criteria they considered most important when making a choice in the given product categories. From a list of criteria, ten for each product category, they indicated the three most important—-for example, "Indicate which three criteria you find most important when making a choice between a number of apartments: distance, condition, neighborhood, size, number of apartments in the building, cleanliness of communal rooms, furniture, internet connection, television, garden." We measured preference fluency through the time needed to decide upon these criteria.

Results and Discussion 
Choice results. For each participant, we count the number of times he or she chooses a compromise option (option $\mathrm{B}$, ranging from 0 to 2 ). This number differs significantly across conditions $(\mathrm{F}(2,100)=4.52, p<.02)$.

Consistent with Study 2, the choice data indicate that participants in the selfawareness condition $(\mathrm{M}=0.71)$ opt for option $\mathrm{B}$ less often than participants in the control condition $(\mathrm{M}=1.10 ; \mathrm{F}(1,71)=7.41, p<.01)$, and their choice pattern does not differ significantly from that in the preference awareness condition $(\mathrm{M}=.70 ; \mathrm{F}(1,66)=$ $.01, \mathrm{NS})$, consistent with the idea that private self-awareness increases preference fluency. The mean number of choices of option B in the preference awareness condition is significantly smaller than the mean in the control condition $(\mathrm{F}(1,63)=5.60, p<.03)$.

Preference fluency. Further analyses confirm the hypothesized process. That is, we find a significant effect of the experimental condition on preference fluency, or the time participants need to decide which attributes are most important $(\mathrm{F}(2,100)=5.83, p<$ .01). Participants in the self-awareness condition need significantly less time $(\mathrm{M}=12.70$ sec) than participants in the control condition $(\mathrm{M}=15.61 \mathrm{sec} ; \mathrm{F}(1,71)=8.22, p<.01)$ and as little time as participants in the preference awareness condition $(M=12.65 \mathrm{sec}$; $\mathrm{F}(1,66)=.02, N S)$. Furthermore, as we expected, participants in the preference awareness condition need less time than those in the control condition $(\mathrm{F}(1,63)=10.41$, $p<.01)$

Further analyses reveal that increased preference fluency, as reflected in the reduced time needed to find the most important attributes, mediates the effect of the selfawareness manipulation on the number of choices of option B. Thus, including the average time needed to decide on the most important attributes in the analysis weakens the effect of self-awareness $(\mathrm{F}(1,70)=2.96, p<.10)$, reducing the mean squares $(\mathrm{MS})^{2}$ 
for this effect by $64 \%$. The effect of average time also is significant $(\mathrm{F}(1,70)=9.90, p$ $<.01)$. We confirm these results with a significant Sobel test (Preacher and Hayes 2004) that indicate $\mathrm{Z}=-2.06$ and $p<.05$. We thus conclude that increased preference fluency is responsible for the decreased tendency to select compromise options due to preference awareness or self-awareness manipulations.

In summary, we again demonstrate that participants' self-awareness influences the tendency to opt for compromise options. Moreover, the data from Study 3 offer direct evidence that increased preference fluency mediates the impact of self-awareness on choice. Private self-awareness, through preference fluency, decreases a person's tendency to select the middle option as a means to resolve choice difficulties. In this way, increased self-awareness seems to have the same effect on the selection of compromise options as increased awareness of preferences in general.

Although these data are consistent with our theoretical predictions, they offer only indirect evidence of the impact of self-awareness on a consumer's decision processes; they cannot rule out an alternative explanation based on distraction effects. That is, selfaware participants may get distracted from the experimental stimuli by their focus on themselves, in which case they could process the stimuli less carefully and engage in lexicographic decision making, such that they choose the alternative that is best on a certain attribute (Svenson 1990). Because context effects depend on the extent to which consumers engage in effortful, compensatory trade-offs of alternatives (Dhar, Nowlis, and Sherman 2000), we posit that diminished effort might provide an alternative explanation for these effects. To understand consumers' decision processes, we examine their information search patterns more directly as a function of private self-awareness in Study 4 . 


\section{STUDY 4}

In this study, we attempt to obtain more direct evidence about the pivotal role of preference fluency in terms of the effect of private self-awareness on choice. First, we operationalize preference fluency more directly than in Study 3 by measuring consumers' information search patterns directly. Second, we manipulate preference fluency directly by altering the ambiguity of product attribute information and investigate whether this approach moderates the effect of private self-awareness on choice.

To achieve insight into information search patterns (i.e., processing by attribute versus processing by alternative), we use the Mouselab paradigm (Payne, Bettman, and Johnson 1993), which assumes that information search patterns indicate underlying decision processes. Previous research reveals that consumers tend to start with (easier) attribute-based evaluations and comparisons to form attribute-based preferences, then apply these preferences to find the alternative that best matches their ideal point (Bettman and Park 1980; Chernev 2003). In other words, information processing becomes more alternative-based later in the decision process; therefore, consumers with articulated personal preferences tend to adopt more alternative-based processing strategies (Chernev 2003). The more insight a person has into his or her personal preferences, the more he or she can process the information by alternatives and then halt the evaluation process once he or she reaches an alternative that is sufficiently close to an ideal. This process leads to more selective evaluations (Chernev 2003).

Manipulating preference fluency more directly, we also obtain more evidence about the pivotal role of preference fluency with regard to the effect of private self-awareness on choice. Specifically, we make product attribute information more ambiguous by 
presenting the attribute values as a range rather than as specific values (Dhar and Simonson 2003; Kahn and Meyer 1991). Consider, for example, a choice between two appliances that differ in price and user friendliness. In one case, we express user friendliness as a point (e.g., 50 versus 70), whereas in another, it appears as a range (e.g., 50-65 versus 70-85). According to Dhar and Simonson (2003), the range of values increases the difficulty of forming an attitude about a specific option. By presenting the attribute levels as ranges, we make it more difficult for participants to construct well-defined preferences about a given choice set. This manipulation matches many real-life situations in which product attribute information is ambiguous, such as when consumers must weigh objective product attribute information against diverging subjective reviews of the same products or when the evaluations are verbal instead of numerical. Our moderation manipulation thus offers information about a potential boundary condition of the private self-awareness effect.

Although making product attribute information more ambiguous does not affect consumers' awareness of the importance of attributes, it reduces preference fluency directly by making the distinction between the options more blurry. Therefore, our framework enables us to predict that a state of private self-awareness, even though it increases awareness of the relative importance of attributes (see Study 2), will not decrease the tendency to select the compromise option when product attribute information is ambiguous.

Furthermore, because we recognize that a focus on the self may distract consumers from the product, and hence hinder them from engaging in the compensatory decision making that often underlies the selection of compromise options (Dhar 1996), we attempt to rule out this alternative explanation. Distraction would lead to lexicographic 
decision making, which is characterized by accelerated processing (less time per information acquisition) and more attribute-based processing. When time pressures or cognitive loads increase, people tend to switch strategies from a more depth-oriented (alternative-based) to a more breadth-oriented (attribute-based) pattern of processing (Payne, Bettman, and Johnson 1988).

\section{Method}

A total of 117 undergraduate students (35 men, 82 women) participated in this experiment. We manipulated two factors (self-awareness $\times$ range); for self-awareness, we used the same manipulation as in Study 2 (i.e., story writing task).

All participants made choices in two product categories: barbecues and laptops. The barbecues featured three attributes, two of which (price and size) appeared as specific values, and we manipulated the representation of the third attribute, user friendliness. In the no-range condition, it was a specific value (rating), whereas in the range condition, it equaled a range of values, such that the minimum ratings were at least as good as the values in the no-range condition. Thus, though it was more difficult to construct personal preferences for each choice alternative, the attributes were as least as attractive and no more risky than in the no-range condition (Dhar and Simonson 2003). Similarly, we represented laptops with three attributes: two (weight and processor speed) specific and one (design rating) either specific or a range of values (see Appendix D).

The experiment employed MouselabWEB (Willemsen and Johnson 2005). The introduction screen told participants how to access information in the boxes using the mouse. Participants became familiar with the information search task and received a sample table containing product attribute information, similar to procedures used in the study. Next, participants received the actual choice sets, with product information 
presented in a product-attribute matrix, in which the product information appeared in columns and the attribute information was in rows. The attribute values initially were hidden but could be viewed by moving a mouse-controlled cursor over the relevant box. MouselabWEB recorded which boxes the participants opened, in what sequence, and the time they spent in each box.

Building on previous research using Mouselab methodology (e.g., Dhar, Nowlis, and Sherman 2000; Payne, Bettman, and Johnson 1988), we calculated three indices of information acquisition strategy: (1) the total amount of information acquired, (2) average time spent acquiring each piece of information, and (3) the information search pattern (i.e., by attribute versus by alternative).

To measure the amount of information acquisition (ACQ), we counted the total number of times participants opened information boxes before making their choice. The time per acquisition (TPERACQ) measure divides the total time spent during the choice task by the total number of acquisitions. Consumers' search patterns equal the number of alternative-based transitions (i.e., transitions from one attribute to another within the same alternative) minus the number of attribute-based transitions (i.e., transitions comparing one attribute level across product options), divided by the total number of transitions. Thus, the measure of the relative use of alternative- versus attribute-based processing, referred to as PATTERN, ranges from -1.0 to +1.0 , such that more negative values represent more attribute-based processing.

\section{Results and Discussion}

Choice results. We count the number of times participants choose the compromise alternative, ranging from 0 to 2 . We find a significant interaction between range and self-awareness $(\mathrm{F}(1,113)=5.58, p<.05)$, which indicates that the effect of self- 
awareness on choice depends on the range condition. Consistent with previous studies, in the no-range condition, highly self-aware participants are less likely to choose the compromise alternative $(\mathrm{M}=.81)$ than are participants in the low self-awareness condition $(\mathrm{M}=1.38 ; \mathrm{F}(1,51)=7.26, p<.01)$. In the range condition, however, we find no significant difference in the choices between the low self-awareness condition $(\mathrm{M}=$ $1.42)$ and the high self-awareness condition $(\mathrm{M}=1.48 ; \mathrm{F}(1,62)=.13, \mathrm{NS})$. Thus, reducing preference fluency seems to mitigate the baseline reduction effect of private self-awareness on the compromise choice, as the broad ranges hinder participants from constructing well-defined personal preferences. We summarize the data in Figure1.

\section{Insert Figure 1 about here}

Processing results. We next analyze the ACQ (amount of information acquisition), TPERACQ (time per acquisition), and PATTERN (relative dominance of alternativebased switches) process measures. Higher values of ACQ indicate more comprehensive processing, whereas lower values tend to be associated with more selective processing. Higher values of TPERACQ also suggest accelerated processing, and higher PATTERN values imply a more alternative-based decision strategy. On average, participants check information 32.13 times for an average of 835 milliseconds per acquisition. The average value of PATTERN, -.09, indicates a slight dominance of attribute-based switches.

\section{Insert Table 2 about here}

An ANOVA of ACQ reveals a marginally significant effect of self-awareness ( $\mathrm{F}(1$, $113)=2.77, p<.10$ ). However, we find a significant interaction between self-awareness and range $(\mathrm{F}(1,113)=5.23, p<.05)$ that indicates this effect of self-awareness depends on the range condition. In the no-range condition, highly self-aware participants ( $\mathrm{M}=$ 26.2) are significantly more selective in their processing behavior than are low self- 
aware participants $(\mathrm{M}=34.6 ; \mathrm{F}(1,51)=6.57, p<.05)$; the same is not true in the range condition, in which participants in the high $(\mathrm{M}=34.3)$ and low $(\mathrm{M}=33.0)$ selfawareness conditions examine the same amount of information $(\mathrm{F}(1,1,62)=.25$, NS). A lower value for ACQ, in principle, may follow from a lower motivation to process information, but TPERACQ does not reveal a main effect of self-awareness $(\mathrm{F}(1,113)=$ $1.09, \mathrm{NS})$ or an interaction effect for self-awareness and range $(\mathrm{F}(1,113)=1.29, \mathrm{NS})$. That is, only the range manipulation influences this measure significantly, such that participants in the range condition spend more time per acquisition $(M=944)$ than do participants in the no-range condition $(\mathrm{M}=708 ; \mathrm{F}(1,113)=7.72, p<.01)$, which should be no surprise because information in the range condition is more complex than that in the no-range condition.

An analogous ANOVA on the PATTERN data shows that search patterns are affected both by the self-awareness manipulation $(\mathrm{F}(1,113)=5.88, p<.05)$ and the range manipulation $(\mathrm{F}(1,113)=8.14, p<.01)$. More important, the analysis reveals a significant interaction between self-awareness and range $(\mathrm{F}(1,113)=6.87, p<.01)$. The data thus indicate that in the no-range condition, highly self-aware participants are more likely to search by alternative $(M=.29)$ than are low self-aware participants $(\mathrm{M}=$ $-.18 ; \mathrm{F}(1,51)=10.66, p<.01)$. In the range condition, both highly self-focused participants $(\mathrm{M}=-.22)$ and low self-focused participants $(\mathrm{M}=-.20)$ tend to search by attribute. We summarize these data in Table 2.

These search pattern measures offer convergent data, showing that highly self-aware consumers prefer a more selective, more alternative-based search than do low selfaware consumers. However, this effect only occurs when people can construct welldefined preferences for the different options: In the range condition, in which it is much 
harder to construct personal preferences and preference fluency remains low by design, we find no differences between the high self-awareness and low self-awareness groups.

These data therefore provide more insight into the choice processes of self-aware consumers. Although self-focused people opt for less comprehensive searches, they do not engage in accelerated processing, which is characteristic of the use of heuristics (Payne, Bettman, and Johnson 1988).

The latter result also receives confirmation from the PATTERN data, which imply that self-aware consumers are not more lexicographic in their choices. If highly selffocused people merely chose the alternative with the highest value on their most important attribute, we would find that they engaged in more attribute-based analysis than did low self-focused individuals. Rather, the data confirm our assumption that private self-awareness enhances preference fluency: Consumers who are more conscious of their personal preferences can process the information by alternative and evaluate choice options in a more selective manner, which lowers the total amount of processing.

\section{GENERAL DISCUSSION}

\section{Summary}

At the core of self-awareness theory lies the idea that self-aware people try to decrease the discrepancies between their current behavior and personal standards. Our research shows that this tendency has a direct and consequent impact on consumer decision making. The four studies we report yield convergent evidence: With greater selfawareness, consumers are more willing and able to rely on their personal preference weights. By this, privately self-aware consumers are less inclined to opt for a varied choice set and less likely to select compromise options. 
The theoretical account for these data relies on the notion that self-aware consumers are more conscious of their personal preferences, which makes it easier for them to form preferences in a specific choice task. This finding also is consistent with original selfawareness theory, which reveals that self-aware people are more conscious of their presence, attitudes, and beliefs (Gibbons 1990).

\section{Limitations and Further Research}

Wilson and colleagues (1989) report, across various experiments, that reasoning and introspection reduce the level of attitude-behavior consistency, which leads to decisions that are less satisfying and less optimal (Wilson and Schooler 1991). Through careful introspection of preferences, consumers might even obscure the basically affective nature of preferences and make decisions that are suboptimal and unsatisfying. Careful trade-off comparisons also might obscure global assessments and less verbalized aspects of the alternatives that actually are more important in a choice context (Dhar, Nowlis, and Sherman 2000; Dijksterhuis et al. 2006). However, self-awareness should not be mistaken for introspection or a longer thinking process. As Study 4 reveals, selfaware participants are more selective in their processing. Together with our results, the finding that thinking hard may harm, rather than help, decision making raises the question of whether thinking hard actually induces neglect for real preferences.

Other suggestions for further research follow naturally from the limitations of this research. First, despite our efforts to make the procedure unobtrusive and the choices as realistic as possible, our participants make their decisions in a lab environment. The hypotheses probably could not be tested adequately in a less controlled environment, though additional research could supplement our experimental data by examining 
secondary data that might provide further relevant evidence. For example, scanner data might indicate whether mirrors in a store influence choice making.

Second, affective correlates (e.g., negative mood) might help explain the influence of private self-awareness on choice making. Seeing oneself in a mirror could induce a negative mood (Fejfar and Hoyle 2000), which might influence behavioral consistency. However, Studies 2 and 3, in which we manipulate self-awareness with a mirror and a story writing task, do not indicate any significant effect of private self-awareness manipulation on positive or negative affect.

In summary, contextual private self-awareness appears able to increase the ease with which consumers construct personal preferences, which makes them less susceptible to contextual factors. However, though we focus on two conflict resolution mechanisms, our framework also might be extended to other mechanisms (e.g., attribute balance choice; Chernev 2005). Furthermore, our framework does not imply that private selfawareness suppresses all conflict resolution mechanisms. For example, an asymmetrically dominating alternative should not lose any significant share, because consumers tend to believe that their preference for that option is based on its superior values on a particular dimension (Dhar and Simonson 2003).

\section{Managerial Implications}

On a more practical note, our findings reveal the substantive power of selfawareness. On the one hand, intentional manipulations of consumers' self-awareness could prove beneficial; by increasing their self-awareness, marketers could enable consumers to make choices that match their personal preferences better, which might result in higher choice satisfaction. Conceivably, greater self-awareness could be achieved by, for example, strategically placing mirrors in a store, addressing the 
customer by name, or other means that prime a consumer's self-awareness. On the other hand, marketers must understand that the general advantage of some selling strategies (e.g., presenting a product as a compromise option) can disappear for self-attentive consumers. In addition, some conditions make it harder to induce a consumer to choose a certain product. Thus, certain selling environments likely benefit from selling strategies that draw attention away from the self. In general, our research implies that marketers should consider the side effects of their store arrangements (e.g., mirrors) or sales interactions (e.g., small talk) on self-awareness, because any incidental cue that redirects the consumer's focus inward will result in greater self-awareness and, consequently, increased preference fluency. 
Argo, Jennifer J., Darren W. Dahl, and Rajesh V. Manchada (2005), “The Influence of a Mere Social Presence in a Retail Context," Journal of Consumer Research, 32 (September), 207-212.

Ariely, Dan and Jonathan Levav (2000), "Sequential Choice in Group Settings: Taking the Road Less Travelled and Less Enjoyed," Journal of Consumer Research, 27 (December), 279-90.

Berkowitz, Leonard (1987), "Mood, Self-Awareness; and Willingness to Help,” Journal of Personality and Social Psychology, 52 (4), 721-29.

Bettman, James R. and C. Whan Park (1980), "Effects of Prior Knowledge and Experience and Phase of the Choice Process on Consumer Decision Processes: A Protocol Analysis," Journal of Consumer Research, 7 (December), 234-48.

Buss, Arnold H. (1980), Self-Consciousness and Social Anxiety. San Francisco: Freeman.

Carver, Charles S. and Michael F. Scheier (1978), "Self-Focusing Effects of Dispositional Self-Consciousness, Mirror Presence, and Audience Presence," Journal of Personality and Social Psychology, 36 (3), 324-32. 
to Human Behavior. New York: Springer-Verlag.

Chernev, Alexander (2003), "Product Assortment and Individual Decision Processes," Journal of Personality and Social Psychology, 85 (1), 151-62.

— (2005), "Context Effects Without a Context: Attribute Balance as a Reason for Choice," Journal of Consumer Research, 32 (September), 213-223.

Dhar, Ravi (1996), “The Effect of Decision Strategy on Deciding to Defer Choice,” Journal of Behavioral Decision Making, 9 (4), 265-81.

— Stephen M. Nowlis, and Steven J. Sherman (2000), "Trying Hard or Hardly Trying: An Analysis of Context Effects in Choice," Journal of Consumer Psychology, 9 (4), 1989-200. and Itamar Simonson (2003), "The Effect of Forced Choice on Choice," Journal of Marketing Research, 40 (2), 146-60.

Dijksterhuis, Ap, Maarten W. Bos, Loran F. Nordgren, and Rick B. van Baaren (2006), "On Making the Right Choice: The Deliberation-Without-Attention Effect," Science, 311 (5763), 1005-1007. 
and Ad Van Knippenberg (2000), "Behavioral Indecision: Effects of Self-Focus on Automatic Behavior," Social Cognition, 18 (1), 55-74.

Duval, Shelley and Robert A. Wicklund (1972), A Theory of Objective Self-Awareness. New York: Academic Press.

Fejfar, Michele C. and Rick H. Hoyle (2000), "Effect of Private Self-Awareness on Negative Affect and Self-Referent Attribution: A Quantitative Review," Personality and Social Psychology Review, 4 (2), 132-42.

Fenigstein, Allan and Michael P. Levine (1984), "Self-Attention, Concept Activation, and the Causal Self," Journal of Experimental Social Psychology, 20 (3), 231-45.

—, Michael F. Scheier, and Arnold H. Buss (1975), "Public and Private SelfConsciousness: Assessment and Theory," Journal of Consulting and Clinical Psychology, 43 (4), 331-37.

Froming, William J., G. Rex Walker, and Kevin J. Lopyan (1982), "Public and Private Self-Awareness: When Personal Attitudes Conflict with Societal Expectations," Journal of Experimental Social Psychology, 18 (5), 476-87.

Gibbons, Frederick X. (1990), "Self-Attention and Behavior: A Review and Theoretical Update," Advances in Experimental Social Psychology, 23, 249-303. 
Hormuth, Stefan E. (1982), "Self-Awareness and Drive Theory: Comparing Internal Standards and Dominant Responses," European Journal of Social Psychology, 12 (1), $31-45$.

Kahn, Barbara E. and Robert J. Meyer (1991), “Consumer Multiattribute Judgments Under Attribute-Weight Uncertainty," Journal of Consumer Research, 17 (4), 508-522.

Kahneman, Daniel and Jackie Snell (1992), "Predicting a Changing Taste: Do People Know What They Will Like?” Journal of Behavioral Decision Making, 5 (3), 187-200.

May, Rollo (1967), Psychology and the Human Dilemma, New York, Van Nostrand Reinhold.

Mehrabian, Albert and James A. Russell (1974), An Approach to Environmental Psychology, Cambridge, MA: MIT Press.

Novemsky, Nathan, Ravi Dhar, Norbert Schwarz, and Itamar Simonson (2007), "Preference Fluency in Choice," Journal of Marketing Research, 19 (August), 347-56.

Payne, John W., James R. Bettman, and Eric J. Johnson (1988), “Adaptive Strategy Selection in Decision Making," Journal of Experimental Psychology: Learning, Memory and Cognition, 14 (3), 534-52. 
— _ _ - (1993), The Adaptive Decision Maker, New York:

Cambridge University Press.

Pham, Michel T. and A.V. Muthukrishnan (2002), "Search and Alignment in Judgment Revision: Implications for Brand Positioning," Journal of Marketing Research, 39 (1), $18-30$.

Preacher, Kristopher J. and Andrew F. Hayes (2004), "SPSS and SAS Procedures for Estimating Indirect Effects in Simple Mediation Models," Behavioral Research Methods, Instruments, \& Computers, 36 (4), 717-31.

Ratner, Rebecca and Barbara E. Kahn (2002), “The Impact of Private Versus Public Consumption on Variety-Seeking Behavior," Journal of Consumer Research, 29 (September), 246-57.

Simonson, Itamar (1989), "Choice Based on Reasons: The Case of Attraction and Compromise Effects,” Journal of Consumer Research, 16 (September), 158-74.

_ (1990), “The Effect of Purchase Quantity and Timing on Variety-Seeking Behavior," Journal of Marketing Research, 27 (May), 150-62.

Svenson, Ola (1990), "Some Propositions for the Classification of Decision Situations," in Contemporary Issues in Decision Making, K. Borcherding, O.I. Larichev, and D.M. Messick, eds. Amsterdam: Elsevier. 
Vallacher, Robin R. and Maurice Solodky (1979), “Objective Self-Awareness, Standards of Evaluation, and Moral Behavior," Journal of Experimental Social Psychology, 15 (3), 254-62.

Wilson, Timothy D., Dana S. Dunn, Dolores Kraft, and Douglas J. Lisle (1989), "Introspection, Attitude Change, and Attitude-Behavior Consistency: The Disruptive Effects of Explaining Why We Feel the Way We Do," Advances in Experimental Psychology, 22, 289-343.

and Jonathan W. Schooler (1991), "Introspection Can Reduce the Quality of Preferences and Decisions," Journal of Personality and Social Psychology, 60 (2), 18192.

Willemsen, Martijn C. and Eric Johnson (2005), "MouselabWEB," (accessed August, 2007) [available at http://www.mouselabWEB.org]. 
${ }^{1}$ We report the percentage reduction of the MS of the mediated effect because, according to ANCOVA, changes in the magnitude of the experimental effect $(\omega 2)$ reflect changes in the MS error, which are unrelated to the experimental factor of interest (Pham and Muthukrishnan 2002).

${ }^{2}$ On the basis of the number of option Bs chosen and the preference awareness measure, we calculate a Mahalanobis distance (generalized distance measure that takes into account correlations between the different variables) for each participant to determine outliers. This Mahalanobis distance follows a Chi-square distribution, with 1 degree of freedom. All participants with a distance greater than the .990 fractile are considered outliers; we identify two such participants. 
Figure 1

THE INFLUENCE OF PRIVATE SELF-AWARENESS AND CHOICE DIFFICULTY (RANGE) ON THE SELECTION OF COMPROMISE OPTIONS (STUDY 4)

Number of

Compromise options

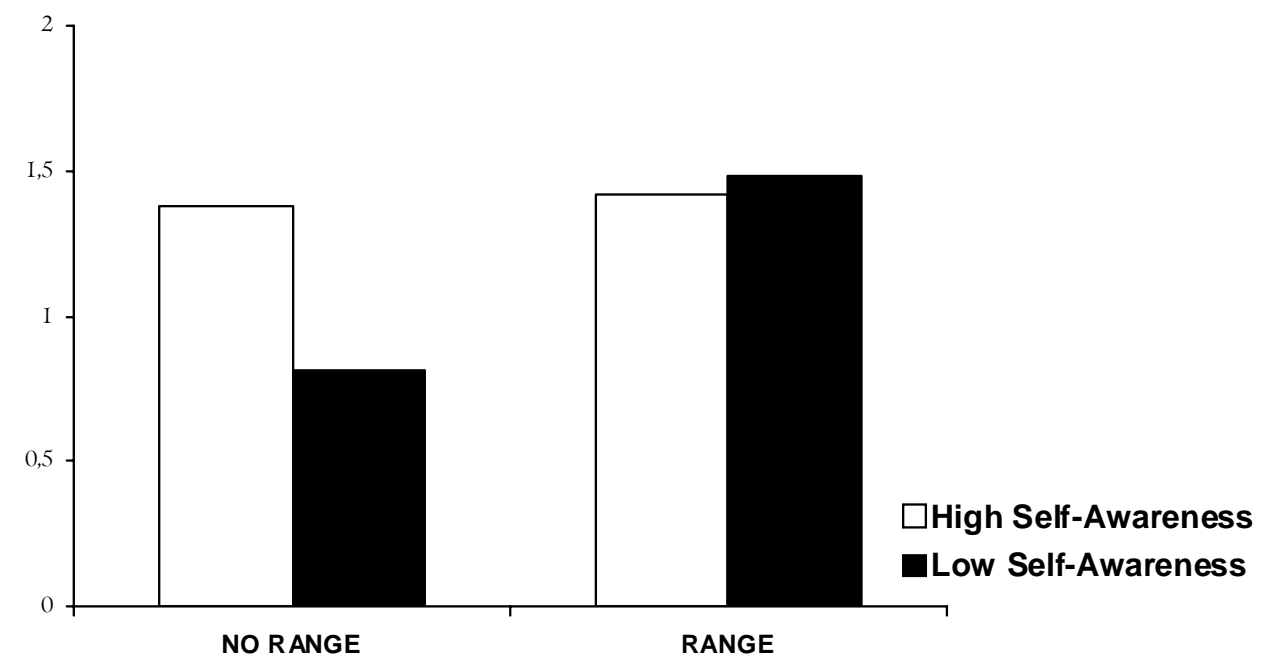


Table 1

THE INFLUENCE OF PRIVATE SELF-AWARENESS ON THE RELATIVE SHARE

OF A COMPROMISE OPTION (STUDY 2)

\section{Relative share when}

not

Relative share

Product

compromise

when compromise

Apartment

\begin{tabular}{ccc}
\hline Low Self-Awareness & $25 \%^{\mathrm{a}}$ & $80 \%^{\mathrm{b}}$ \\
\hline High Self-Awareness & $22 \%^{\mathrm{a}}$ & $30 \%^{\mathrm{a}}$ \\
\hline
\end{tabular}

Mobile phone

\begin{tabular}{ccc}
\hline Low Self-Awareness & $50 \%{ }^{\mathrm{a}}$ & $86 \%{ }^{\mathrm{b}}$ \\
\hline High Self Awareness & $40 \%{ }^{\mathrm{a}}$ & $50 \%{ }^{\mathrm{a}}$ \\
\hline Notes: In any row, cells with no common letters in the superscript are significantly different from each other at $p<.05$. Cells with \\
common letters in the superscript are not significantly different from each other at $p<.05$.
\end{tabular}


Table 2

\section{THE INFLUENCE OF SELF-AWARENESS (SA) AND CHOICE DIFFICULTY \\ (RANGE) ON INFORMATION PROCESSING (STUDY 4)}

\begin{tabular}{lcccc}
\hline \hline & \multicolumn{2}{c}{ No Range } & \multicolumn{2}{c}{ Range } \\
\cline { 2 - 5 } & Low SA & High SA & Low SA & High SA \\
Amount of processing (ACQ) & $34.6^{\mathrm{a}}$ & $26.2^{\mathrm{b}}$ & $33.0^{\mathrm{a}}$ & $34.3^{\mathrm{a}}$ \\
Time per acquisition (TPERACQ) & $712.0^{\mathrm{a}}$ & $704.0^{\mathrm{a}}$ & $851.7^{\mathrm{b}}$ & $1037.6^{\mathrm{b}}$ \\
Dominance of alternative-based & $-.18^{\mathrm{a}}$ & $.29^{\mathrm{b}}$ & $-.20^{\mathrm{a}}$ & $-.22^{\mathrm{a}}$ \\
Switches (PATTERN) & & & & \\
\hline $\begin{array}{l}\text { Notes: In any row, cells with no common letters in the superscript are significantly different from each other at } p<.05 . \text { Cells with } \\
\text { common letters in the superscript are not significantly different from each other at } p<.05 .\end{array}$
\end{tabular}




\section{APPENDIX A \\ PRIVATE SELF-CONSCIOUSNESS SCALE \\ (FEINGSTEIN, SCHEIER, AND BUSS 1975)}

I'm always trying to figure myself out.

Generally, I'm not very aware of myself (-).

I reflect about myself a lot.

I'm often the subject of my own fantasies.

I never scrutinize myself. (-)

I'm generally attentive to my inner feelings.

I'm constantly examining my motives.

I sometimes have the feeling that I'm off somewhere watching myself.

I'm alert to changes in my mood.

I'm aware of the way my mind works when I work through a problem. 


\section{APPENDIX B \\ CONSISTENCY MEASURE USED IN STUDY 1

$$
\zeta=1-\frac{\sum \Delta \text { obs }-\sum \Delta \min }{\sum \Delta \max -\sum \Delta \min }
$$

The $\Delta$ obs is the observed quantity choice, minus the theoretically best quantity choice; $\Delta \mathrm{min}$ is the best quantity choice in practical terms minus the theoretically best quantity choice; and $\Delta \max$ is the worst quantity choice minus the theoretically best quantity choice. The worst quantity choice pattern is the most discrepant behavior a person could display, given his or her ratings. In general, a person would choose the juice he or she has rated worst five times. The theoretically best choice is the choice that contains only those juices to which a person gives the highest score.

This index refers to the difference, summed over the choice set options, between the actual choice pattern and the worst possible choice, compared with the difference between the most and least consistent possible choice. Thus, we compare the deviation of the actual choices from the best choices with the maximum deviation possible on the basis of the ratings. It is not always possible for a consumer to behave theoretically optimally, because participants make integer choices, though the choice rule may imply the choice of a decimal quantity (e.g., .66) of a juice. Therefore, we subtract $\sum(\Delta \mathrm{min})$ in the numerator as well as in the divisor. $\zeta$ ranges between 0 and 1.

\section{Example}




$\begin{array}{lclr}\text { apple } & 3 & \text { apple } & 0 \\ \text { apple-cherry } & 5 & \text { apple-cherry } & 2 \\ \text { lemon } & 4 & \text { lemon } & 1 \\ \text { passion fruit } & 3 & \text { passion fruit } & 0 \\ \text { mango } & 5 & \text { mango } & 2 \\ \text { peach } & 2 & \text { peach } & 0 \\ \text { strawberry } & 1 & \text { strawberry } & 0\end{array}$

\begin{tabular}{|lccc|}
\hline & Theoretically Best & Practically Best & Worst \\
\hline orange & 0 & 0 & 0 \\
\hline apple & 0 & 0 & 0 \\
\hline apple-cherry & 2,5 & 2 & 0 \\
\hline lemon & 0 & 0 & 0 \\
\hline passion fruit & 0 & 0 & 0 \\
\hline mango & 2,5 & 3 & 0 \\
\hline peach & 0 & 0 & 0 \\
\hline strawberry & 0 & 0 & 5 \\
\hline
\end{tabular}

\section{Consistency: .973}

$$
\begin{aligned}
& { }^{\Sigma}(\Delta \text { obs })=(0-0)^{2}+(0-0)^{2}+(2-2,5)^{2}+(1-0)^{2}+(0-0)^{2}+(2-2,5)^{2}+(0-0)^{2}+(0-0)^{2} \\
& { }^{\Sigma}(\Delta \text { min })=(0-0)^{2}+(0-0)^{2}+(2-2,5)^{2}+(0-0)^{2}+(0-0)^{2}+(3-2,5)^{2}+(0-0)^{2}+(0-0)^{2} \\
& \Sigma_{(\Delta \text { max })}=(0-0)^{2}+(0-0)^{2}+(0-2,5)^{2}+(0-0)^{2}+(0-0)^{2}+(0-2,5)^{2}+(0-0)^{2}+(5-0)^{2}
\end{aligned}
$$


APPENDIX C

CHOICE SETS USED IN STUDY 2 AND STUDY 3

\begin{tabular}{|c|c|c|c|c|}
\hline \multirow[t]{3}{*}{ Product category } & \multirow[t]{3}{*}{ Attribute 1} & \multirow[t]{3}{*}{ Attribute 2} & \multicolumn{2}{|c|}{ Choice Sets } \\
\hline & & & Two-option & Three-option \\
\hline & & & set & set \\
\hline Apartment/student & & General & & \\
\hline residence & Distance & condition & & \\
\hline Option A & $1 \mathrm{~km}$ & 65 & & $x$ \\
\hline Option B & $2 \mathrm{~km}$ & 80 & $x$ & $x$ \\
\hline Option C & $3 \mathrm{~km}$ & 95 & $x$ & $x$ \\
\hline Mobile phone & Design & Price & & \\
\hline Option A & $\star \star \star *$ & $€ 230$ & $x$ & $x$ \\
\hline Option B & $\star *$ & $€ 190$ & $x$ & $x$ \\
\hline Option C & $\star$ & $€ 150$ & & $x$ \\
\hline
\end{tabular}


APPENDIX D

CHOICE SETS USED IN STUDY 4

\begin{tabular}{|c|c|c|c|c|}
\hline \multirow[t]{2}{*}{ Product category } & \multirow[t]{2}{*}{ Attribute 1} & \multirow[t]{2}{*}{ Attribute 2} & \multicolumn{2}{|c|}{ Attribute 3} \\
\hline & & & No range & Range \\
\hline & & & User & User \\
\hline Barbecue & Price & Diameter & friendliness & friendliness \\
\hline Option A & $€ 50$ & 12 in & 30 & $30-45$ \\
\hline Option B & $€ 150$ & 16 in & 50 & $50-65$ \\
\hline Option C & $€ 250$ & 20 in & 70 & $70-85$ \\
\hline Laptop & Weight & Processor & Design & Design \\
\hline Option A & $1.2 \mathrm{~kg}$ & $1.46 \mathrm{GHz}$ & 85 & $85-100$ \\
\hline Option B & $2.8 \mathrm{~kg}$ & $1.86 \mathrm{GHz}$ & 55 & $55-70$ \\
\hline Option C & $4.4 \mathrm{~kg}$ & $2.2 \mathrm{GHz}$ & 25 & $25-40$ \\
\hline
\end{tabular}

